\title{
IMPLEMENTASI E-CRM (ELECTRONIC CUSTOMER RELATIONSHIP MANAGEMENT) DALAM MENINGKATKAN KEPUASAAN DAN PELAYANAN TERHADAP ANGGOTA KOPERASI PEGAWAI NEGERI MINA UTAMA
}

\author{
Fachreza Haviedz Alqorni ${ }^{1}$, Hestya Patrie ${ }^{2)}$ \\ ${ }^{1}$ Sistem Informasi, Fakultas Teknologi Informasi, Universitas Budi Luhur \\ ${ }^{1,2} \mathrm{Jl}$. Raya Ciledug, Petukangan Utara, Kebayoran Lama, Jakarta Selatan 12260 \\ E-mail : $\underline{\text { fachrezahaviedz@gmail.com }}{ }^{1)}$, hestya.patrie@budiluhur.ac.id ${ }^{2)}$
}

\begin{abstract}
Abstrak
Persaingan bisnis yang semakin berkembang pesat dan perkembangan teknologi informasi menjadi alasan perusahaan untuk mengubah pemikiran perusahaan terhadap bisnis, yang dulunya berorientasi pada keuntungan ke arah faktor-faktor potensial seperti tingkat kepuasan pelanggan. Hal ini merupakan tantangan dan kebutuhan bagi setiap instansi atau lembaga khususnya koperasi agar dapat memberikan pelayanan jasa dengan cepat dan memberikan informasi yang akurat kepada anggota koperasi. Sistem Electronic Customer Relationship Management (E-CRM) menjadi salah satu sistem yang mampu meningkatkan keuntungan kompetitif (Competitive Advantages) melalui kepuasaan yang diperhatikan dalam mempertahankan pelanggan. Berdasarkan penelitian pada Koperasi Mina Utama, masih ada masalah pelayanan anggota dan promosi yang sebenarnya bisa diatasi dengan E-CRM. Masalah-masalah tersebut diantaranya seperti belum adanya media sarana untuk menampung testimoni dan kritik saran anggota, jangkauan promosi sangat sempit, customer service masih kurang maksimal dalam mengingat pertanyaan dan permintaan anggota. Oleh karena itu, penulis membuatkan sistem E-CRM yang dibuat dengan menggunakan bahasa pemrograman SQL, PHP, HTML, dan CSS untuk mengatasi masalah yang ada pada Koperasi Pegawai Negeri Mina Utama.
\end{abstract}

Kata kunci: Koperasi, E-CRM, Aplikasi Berbasis Web, Kepuasaan Anggota

\section{PENDAHULUAN}

Seiring dengan perkembangan zaman yang semakin maju dan modern, kebutuhan akan informasi dan teknologi yang benar, tepat dan akurat sangatlah dibutuhkan oleh suatu instansi atau lembaga, apalagi dengan hadirnya komputer saat ini sebagai alat bantu yang dapat mempermudah pekerjaan manusia. Hal ini merupakan tantangan dan kebutuhan bagi setiap instansi atau lembaga khususnya koperasi agar dapat memberikan pelayanan jasa dengan cepat dan memberikan informasi yang akurat kepada anggota koperasi.

Sistem Electronic Customer Relationship Management (E-CRM) menjadi salah satu sistem yang mampu meningkatkan keuntungan kompetitif (competitive advantages) melalui Kepuasaan yang diperhatikan dalam mempertahankan pelanggan. ECRM adalah suatu aplikasi yang bertujuan untuk menyediakan pelayanan dan mempertahankan loyalitas serta meningkatkan kepuasan pelanggan:[1]

Seperti halnya yang terdapat pada koperasi mina utama khususnya pada bagian penjualan, masih banyak masalah karena belum mengopltimalisasi teknologi informasi seperti E-CRM.

Menurut Buttle dan Maklan, Customer Relationship Management adalah proses mengelola semua aspek interaksi perusahaan dengan pelanggan termasuk pencarian pelanggan, penjualan, layanan.
Aplikasi CRM berusaha memberikan pemahaman serta meningkatkan hubungan perusahaan dengan pelanggan dengan menghubungkan semua pandangan tentang interaksi customer menjadi satu gambaran.[2]

Masalah-masalah tersebut diantaranya seperti belum adanya media sarana untuk menampung testimoni dan kritik saran anggota, jangkauan promosi sangat sempit, customer service dan masih kurang maksimal dalam mengingat pertanyaan dan permintaan anggota.

Berdasarkan latar belakang tersebut, maka dapat diketahui permasalahan riset ini yaitu:

a. Jangkauan promosi masih sempit, yakni didalam toko saja.

b. Tidak ada laporan tentang testimoni, kritik saran, dan customer service.

c. Pelayanan customer service masih dilayani oleh satu orang sehingga pertanyaan dan ajuan dari para anggota seringkali terlupa atau terlewat.

Adapun tujuan penelitian ini yaitu membuat sebuah Sistem Electronic Customer Relationship Management (E-CRM) Pada Koperasi Mina Utama, sehingga dapat memberikan informasi yang akurat dan membantu Koperasi dalam meningkatkan mutu pelayanan dan kualitas pelayanan. 
Menurut Kotler, pelayanan merupakan setiap tindakan atau kegiatan yang dapat ditawarkan oleh satu pihak kepada pihak lain.[3]

5 Faktor penentu kualitas pelayanan yaitu berwujud, empati, daya tanggap, keandalan dan jaminan:[4]

Sementara kepuasaan secara sederhana kepuasan bisa diartikan sebagai upaya pemenuhan sesuatu atau membuat sesuatu memadai.[5]

\section{METODE PENELITIAN}

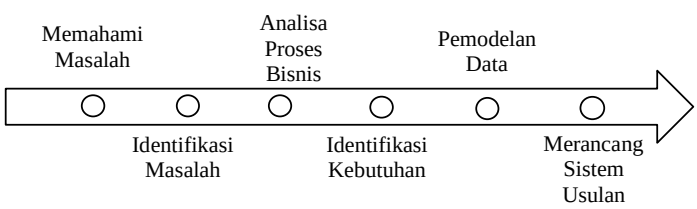

Gambar 1. Tahapan Penelitian

Dalam penyusunan Penelitian ini, terdapat beberapa proses yang dilakukan dalam identifikasi kebutuhan pada Koperasi Pegawai Negeri Mina Utama diantaranya:

a. Memahami permasalahan yang dihadapi oleh Koperasi Pegawai Negeri Mina Utama.

b. Hasil identifikasi digambarkan meggunakan fishbone diagram dimana pada diagram tersebut akan terlihat sebab akibat terjadinya masalah.

c. Mengindentifikasi masalah pada koperasi pegawai negeri mina utama berdasarkan hasil wawancara dan dokumen yang berkaitan.

d. Menggunakan use case diagram dan Activity diagram.untuk menggambarkan hasil identifikasi.

e. Menggambarkan model data sistem dengan Entity Relationship Diagram (ERD) kemudian ditransformasi melalui Logical Record Structure (LRS).

f. Membuat rancangan sistem dengan membuat prototype Electronic Customer Relationship Management (E-CRM).

\section{HASIL DAN PEMBAHASAN}

\subsection{Sistem Berjalan}

Didalam Activity Diagram Ini menjelaskan bahwa ketika seseorang ingin menjadi anggota koperasi harus melalu proses seperti mengisi form pendaftaran.

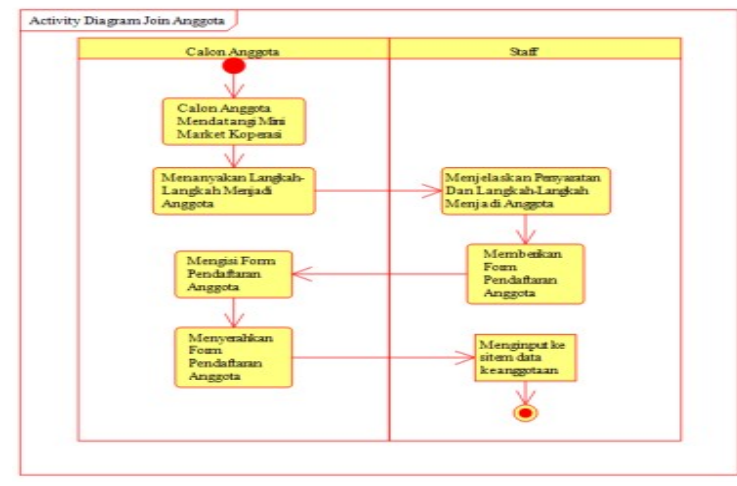

Gambar 2. Activity Diagram Berjalan Join Anggota

Activity Diagram Customer Service ini menjelaskan bahwa sesorang anggota yang ingin mengajukan pertanyaan-pertanyaan atau sekedar memberi sebuah kritik dan saran atas kinerja dari pelayanan koperasi pegawai negeri mina utama.

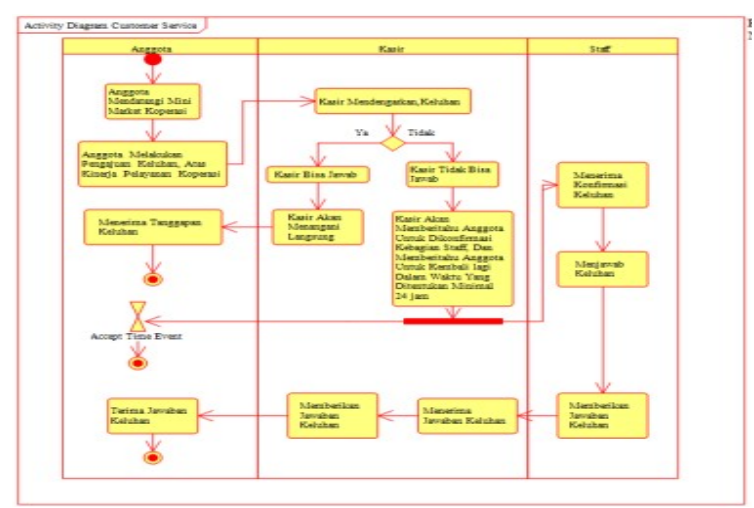

Gambar 3. Activity Diagram Berjalan Customer Service

Activity Diagram Berjalan Promosi ini memberikan penjelasan aktifitas promosi yang dilakukan oleh koperasi tetapi media promosi disediakan oleh supplier.

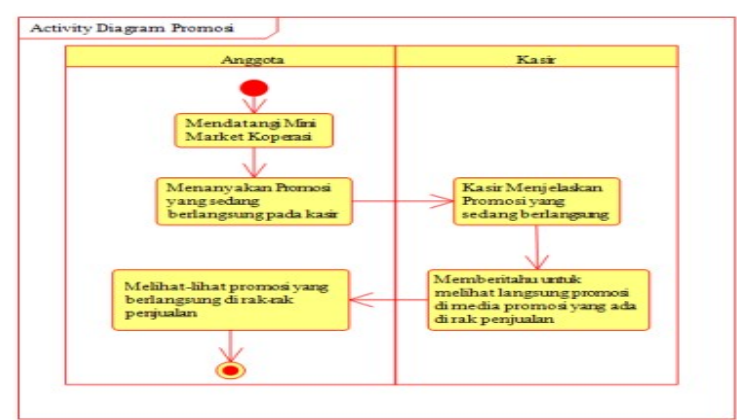

Gambar 4. Activity Diagram Berjalan Promosi

\subsection{Sistem Usulan}

Pada package diagram master terdapat use case view data promosi ,use case view data kritik saran, 
use case view data customer service, use case view data testimoni, dan use case view data anggota

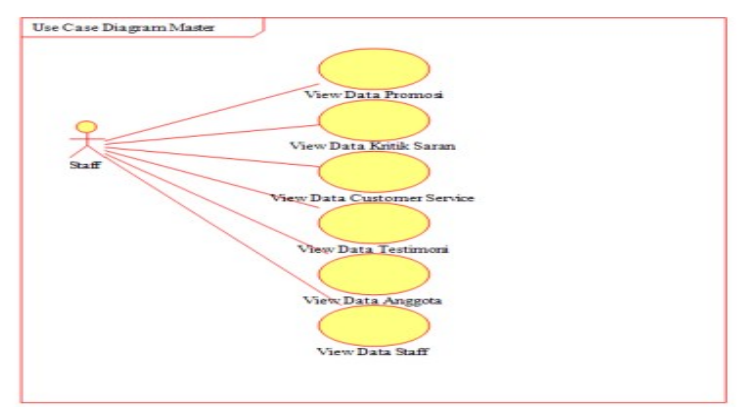

Gambar 5. Use Case Diagram Master

Pada Activity Diagram View Join Us Ini untuk user yang bukan anggota koperasi dan ingin menjadi anggota koperasi bisa melihat syarat-syarat maupun ketentuan menjadi anggota koperasi, user memilih menu join us untuk melihat apa saja yang dibutukan dan dilakukakan ketika ingin menjadi anggota koperasi dan langsung bisa mengklik form cetak, dan sistem akan menampilkan form pendafrtaran anggota koperasi.

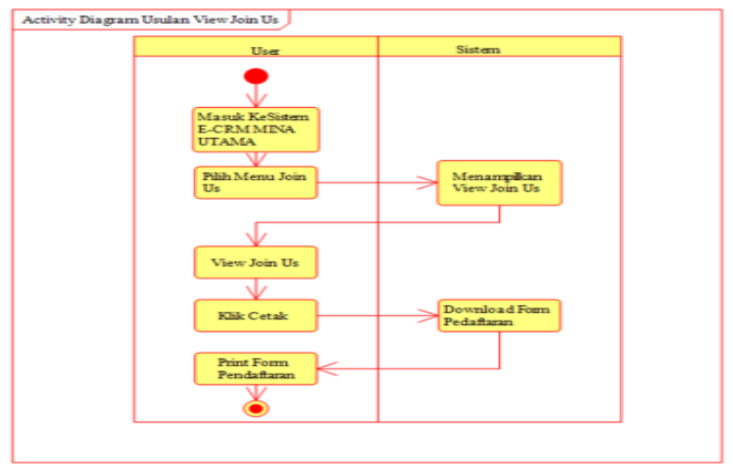

Gambar 6. Activity Diagram Usulan Join Anggota

Pada Activity Diagram kali ini Anggota dapat mengajukan customer service setelah melakukan login, kemudian pilih menu kritik dan saran, sistem akan menampilkan form entry Customer service, Anggota harus mengisi kolom isi Customer service dan memilih mau dihubungi via telpom atau email dan kemudian klik tombol submit, sistem akan menampilkan massage bahwa Anda telah berhasil menginput data Customer service

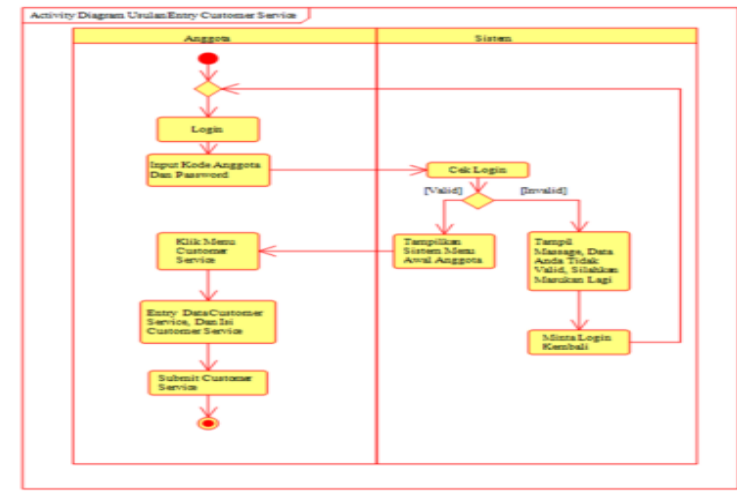

Gambar 7. Activity Diagram Usulan Customer Service

Pada Activity Diagram View Promo user bisa membuka website E-CRM MINA UTAMA dan memilih menu promosi, dam sistem akan menampilkan data promosi, lalu user bisa melihat promo menarik dan terbaru apa saja yang ada pada KPN MINA UTAMA, dan untuk anggota bisa melihat langsung di view promo dan bisa mendapatkan promo menarik khusus anggota yang tersedia.

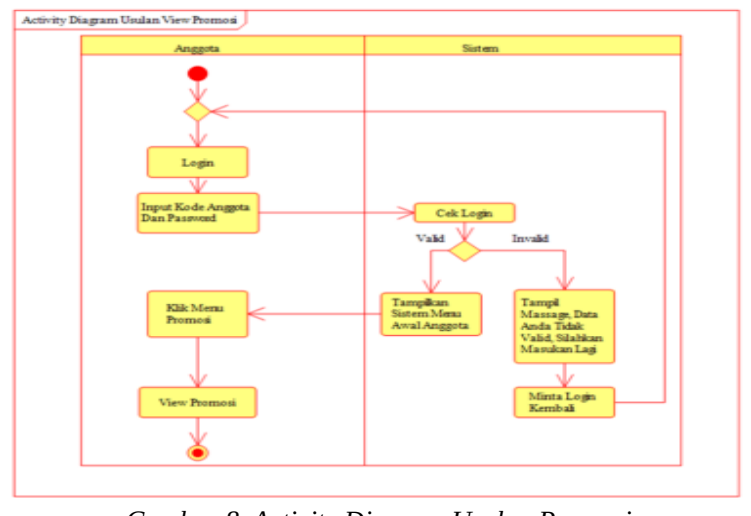

Gambar 8. Activity Diagram Usulan Promosi

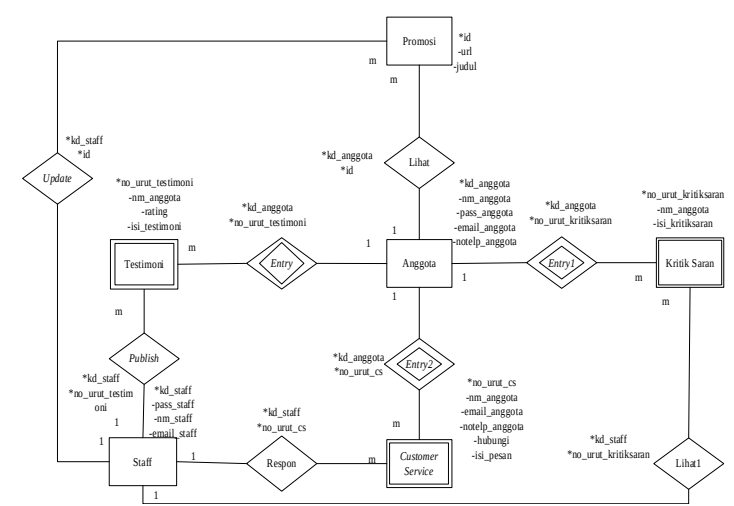




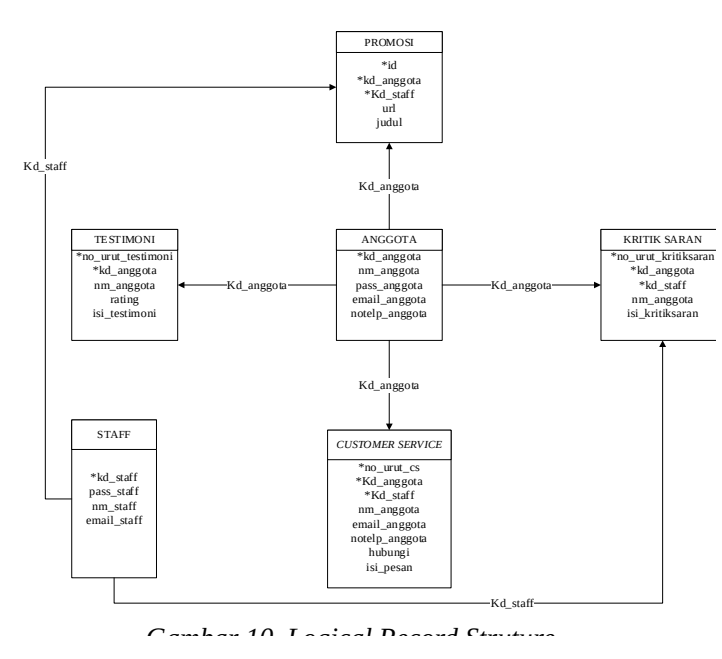

Pada Bagian Header rancangan layar terdapat navigasi menu home, promosi, FAQ, tentang kami, join us,dan login serta register

Pada Bagian body Terdapat Testimoni Anggota Dan Kontak Koperasi Pegawai Negeri Mina Utama

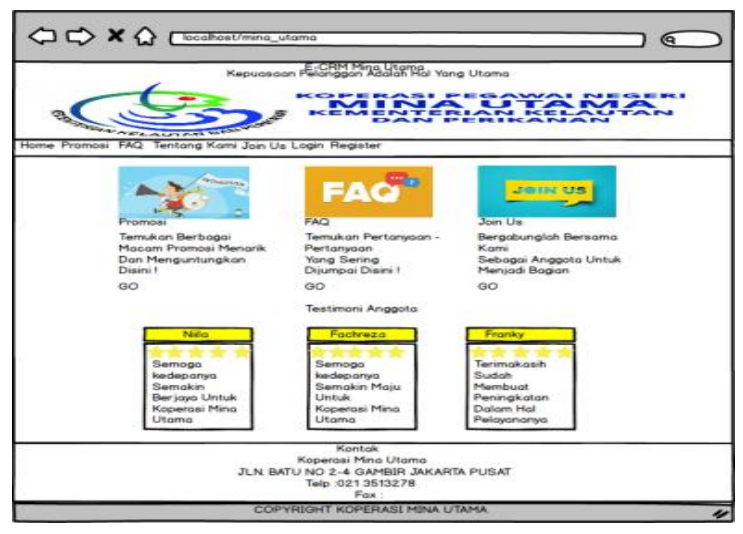

Gambar 11. Tampilan Rancangan Home Anggota

Rancangan Layar Promosi ini bertujuan untuk menarik lagi minat anggota dan meningkatkan kualitas pelayanan terhadap anggota

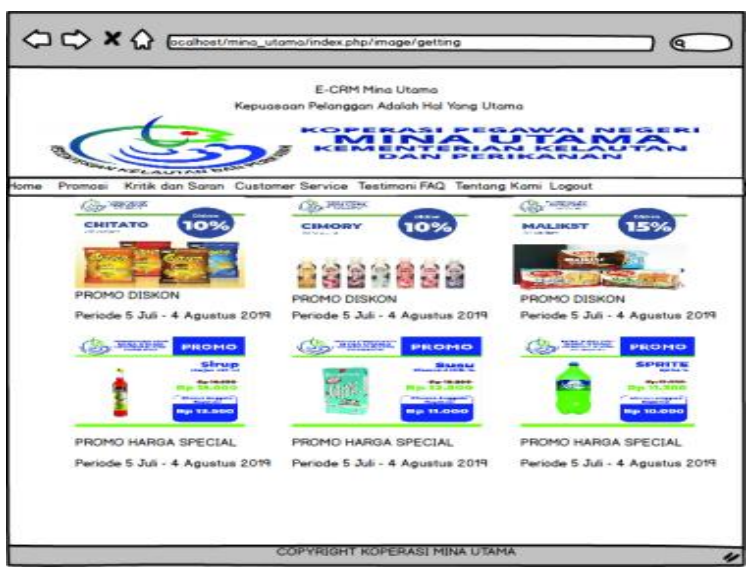

Gambar 12. Tampilan Rancangan Layar Menu Promosi
Rancangan layar ini dikuhusukan untuk anggota koperasi mina utama. Anggota dapat mengemukakan krtik dan saran terhadap koperasi mina utama.

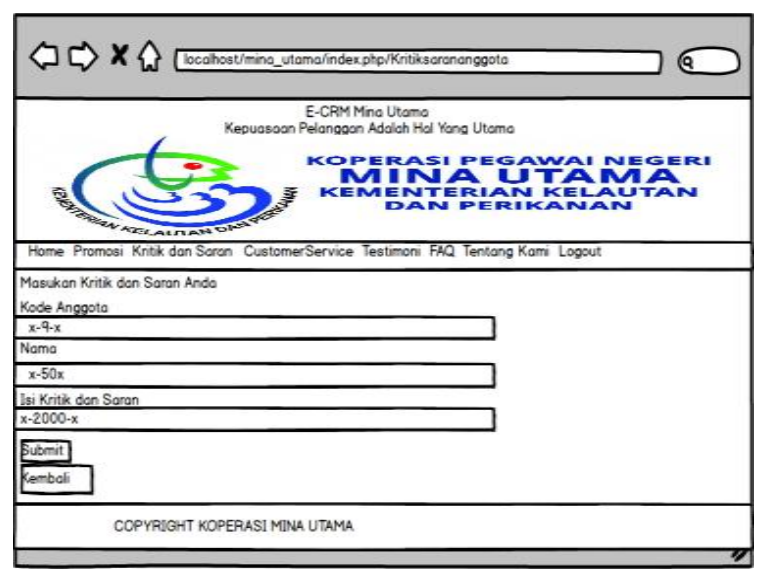

Gambar 13. Rancangan Layar Entry Kritik dan Saran

Rancangan Layar Ini Dikhususkan untuk anggota koperasi mina utama Anggota dapat mengemukakan kritik dan saran terhadap koperasi mina utama

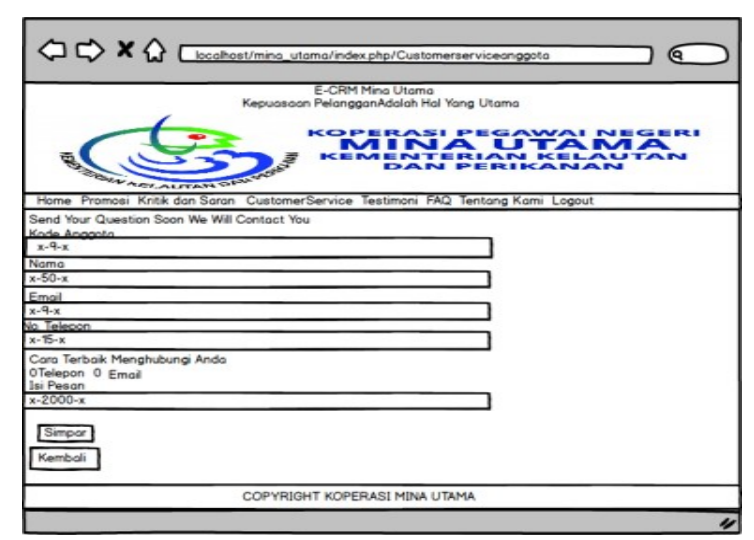

Gambar 14. Rancangan Layar Entry Customer Service

Rancangan Layar Ini dikhususkan untuk anggota koperasi mina utama. Anggota dapat mengemukakan Testimoni terhadap koperasi mina utama 


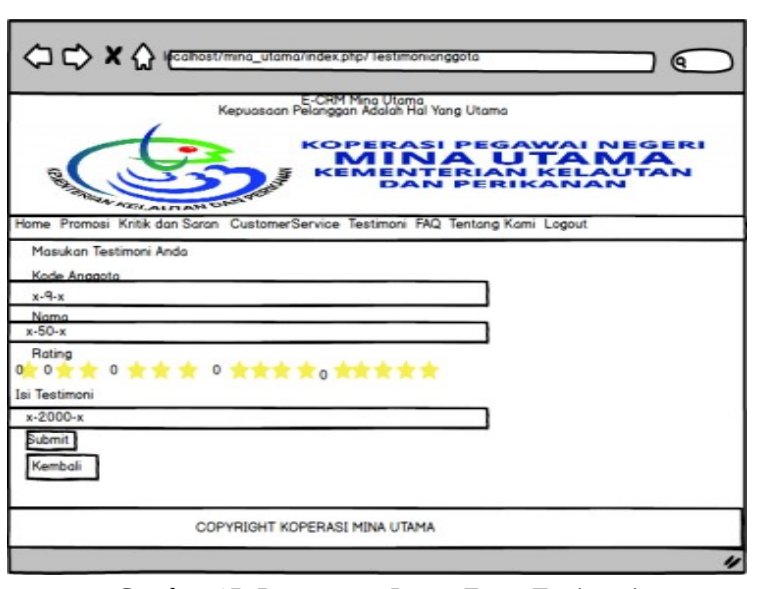

Gambar 15. Rancangan Layar Entry Testimoni

Rancangan Layar Ini Berada dimenu Anggota Koperasi Rancangan Layar Ini dapat digunakan ketika ingin mengetahui pertanyaan-pertanyaan apa saja yang sering ditanyakan terhadap koperasi Koperasi Mina Utama

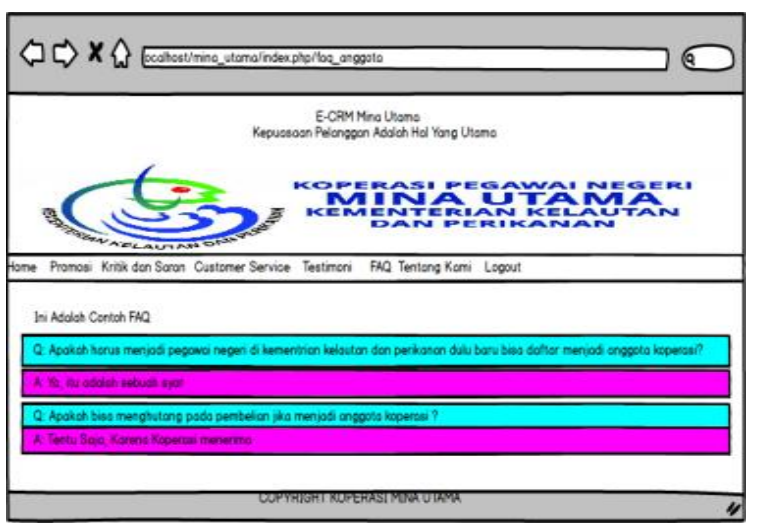

Gambar 16. Rancangan Layar View FAQ

Rancangan Layar Ini Berisikan Sejarah dan Informasi Tentang Koperasi Mina Utama

Rancangan Layar Ini Berada Dimenu Tentang Kami Anggota

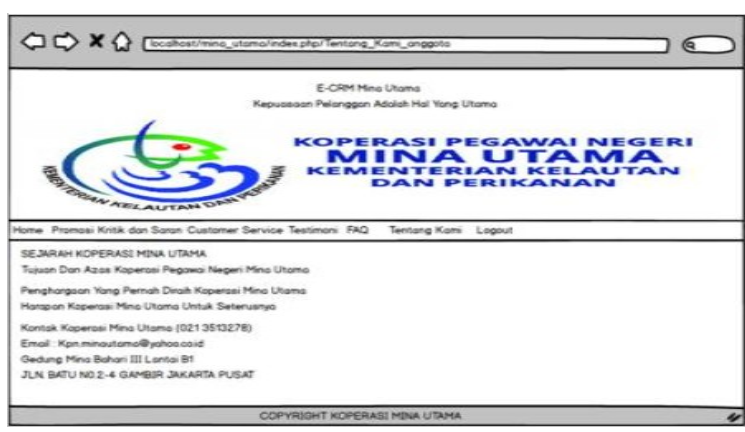

Gambar 17. Rancangan Layar View Tentang Kami

Rancangan Layar Ini Berisikan Informasi Tentang Koperasi Mina Utama dan syarat-syarat ketika ingin menjadi anggota serta memudahkan jika ingin menjadi anggota karena dapat mencetak form pendaftaran

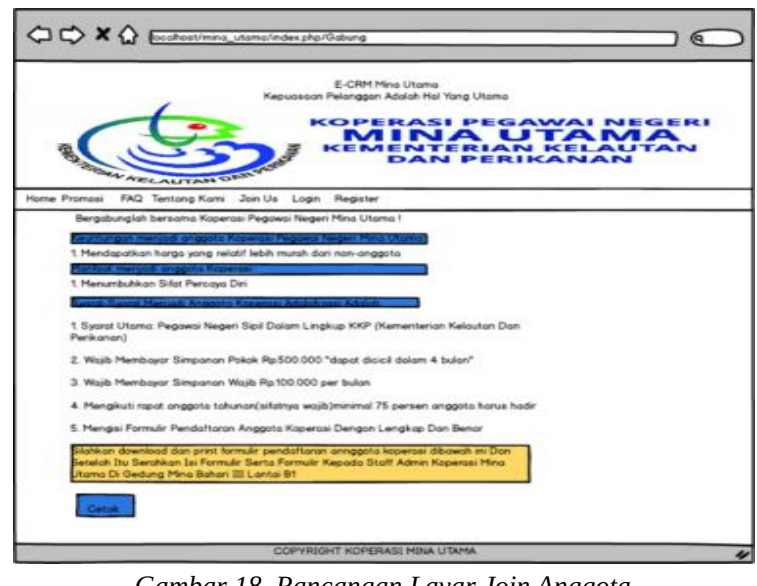

Gambar 18. Rancangan Layar Join Anggota

\section{KESIMPULAN}

Berdasarkan riset dan Analisa yang telah dilakukan, maka penulis dapat menarik kesimpulan dengan beberapa poin sebagai berikut:

a. Penyampaian informasi promosi terbaru yang kurang update serta media promosi yang masih berbentuk cetak masih kurang memuaskan bagi anggota. Maka dari itu dibuatkan menu promosi dimana memudahkan para anggota untuk melihat dan mengetahui promosi-promosi terbaru apa saja yang sedang ada dikoperasi tanpa harus datang langsung.

b. Tidak adanya data laporan tentang kritik saran, testimoni, dan customer service sehingga kurangnya data yang bisa menjadi tolak ukur penilaian kepuasan anggota dan evaluasi kinerja koperasi. Oleh karena itu, di dalam penelitian ini dibuat menu input laporan kritik saran, testimoni dan customer service.

c. Penanganan customer service yang tidak optimal dikarenakan belum adanya sarana yang tepat bagi anggota untuk bertanya dan berpendapat selain datang langsung ke koperasi dan hanya ditangani oleh satu orang untuk seluruh anggota koperasi. Hal tersebut memungkinkan pertanyaan anggota sering ada yang terlupa dan terlewat. Oleh karena itu, didalam penelitian ini dibut menu input customer service untuk bisa memantau dan mendata laporan customer service yang masuk tanpa ada yang terlewat dan terlupakan. 


\section{DAFTAR PUSTAKA}

[1] Kosasi, Sandi. Perancangan Sistem Electronic Customer Relationship Management Untuk Mempertahankan Loyalitas Pelanggan. Jurnal Sistem Infromasi dan Teknologi Informasi. 2015, 92.

[2] Buttle, Francis. and Stan, Maklan. Customer Relationship Management: Concepts and Technologies. 3rd Edition. UK: Florence Production Ltd., 2015

[3] Kotler, Philip. and Keller, Kevin Lane. Marketing Management (15th Edition). England: Pearson Education, Inc., 2016

[4] Tjiptono, Fandy. Pemasaran Jasa-Prinsip, Penerapan,dan Penelitian. Yogyakarta: Andi Offset. 2014

[5] Tjiptono, Fandy. Pemasaran Jasa-Prinsip, Penerapan,dan Penelitian. Yogyakarta: Andi Offset. 2014 